\title{
Application and testing of risk screening tools for nanomaterial risk analysis
}

Grieger, Khara Deanne; Bossa, Nathan; Levis, James W.; von Borries, Kerstin Johanna Felicitas; Strader, Phillip; Cuchiara, Maude; Hendren, Christine Ogilvie; Hansen, Steffen Foss; Jones, Jacob L.

\section{Published in:}

Environmental Science: Nano

Link to article, DOI:

$10.1039 /$ c8en00518d

Publication date:

2018

Document Version

Peer reviewed version

Link back to DTU Orbit

Citation (APA):

Grieger, K. D., Bossa, N., Levis, J. W., von Borries, K. J. F., Strader, P., Cuchiara, M., Hendren, C. O., Hansen, S. F., \& Jones, J. L. (2018). Application and testing of risk screening tools for nanomaterial risk analysis. Environmental Science: Nano, 5(8), 1844-1858. https://doi.org/10.1039/c8en00518d

\section{General rights}

Copyright and moral rights for the publications made accessible in the public portal are retained by the authors and/or other copyright owners and it is a condition of accessing publications that users recognise and abide by the legal requirements associated with these rights.

- Users may download and print one copy of any publication from the public portal for the purpose of private study or research.

- You may not further distribute the material or use it for any profit-making activity or commercial gain

- You may freely distribute the URL identifying the publication in the public portal 
2 M. Ellenbecker, S-J. Tsai, M. Jacobs, M. Riediker, T. Peters, S. Liou, A. Avila, S. Foss Hansen

3 M. Ellenbecker

4 Toxics Use Reduction Institute

5 University of Massachusetts Lowell

$6 \quad$ Lowell, MA 01854, USA

7

8 S-J. Tsai

9 Department of Environmental and Radiological Health Science

10 Colorado State University

11 Fort Collins, CO 80523-1681, USA

12

M. Jacobs

Lowell Center for Sustainable Production

University of Massachusetts Lowell

Lowell, MA 01854, USA

M. Riediker

Institute for Work and Health

Lausanne CH-1066, Switzerland

21

T. Peters

Department of Occupational and Environmental Health

The University of Iowa

Iowa City, IA 52242, USA

26

27

S. Liou

28 National Institute of Environmental Health Sciences

29 Zhunan Town, 35053, Taiwan

30

31

32

A. Avila:

Dept. of Electrical and Electronic Engineering and Centro de Microelectrónica (CMUA),

S. Foss Hansen

37 Department of Environmental Engineering

38 Technical University of Denmark

39 Lyngby, Denmark

40

41

42 Corresponding author: 
M. Ellenbecker

44 ellenbec@turi.org

45 Phone: 1.978.934.3272

46 Fax: 1.978.934.3050

47

48

49

50

51

52

53

54

55

\section{Abstract}

Concern over the health effects from the inhalation of carbon nanotubes (CNTs) has been building for some time, and adverse health effects found in animal studies include acute and chronic respiratory damage, cardiac inflammation, and cancer including mesothelioma, heretofore only associated with asbestos exposure. The strong animal evidence of toxicity requires that the occupational hygiene community develop strategies for reducing or eliminating worker exposures to CNTs; part of this strategy involves the setting of occupational exposure limits (OELs) for CNTs. A number of government agencies and private entities have established OELs for CNTs; some are mass-based, while others rely on number concentration. We review these various proposed standards and discuss the pros and cons of each approach. We recommend that specific action be taken, including intensified outreach to employers and employees concerning the potential adverse health effects from CNT inhalation, the development of more nuanced OELs that reflect the complex nature of CNT exposure, a broader discussion of these issues among all interested parties, and further research into important unanswered questions including optimum methods to evaluate CNT exposures. We conclude that current animal toxicity evidence suggests that strong action needs to be taken to minimize exposures to CNTs, and that any CNT OEL should be consistent with the need to minimize exposures.

\section{Introduction}

Concern over the health effects from the inhalation of carbon nanotubes (CNTs) has been building for some time. A review of articles published over the past dozen years (Boxall et al. 

2007; Donaldson et al. 2006; Kisin et al. 2007; Kisin et al. 2011; Lam et al. 2006; Legramante et al. 2012; Li et al. 2007; Ma-Hock et al. 2009; Muller et al. 2005; Shvedova et al. 2003; Shvedova et al. 2008a; Shvedova et al. 2005; Shvedova et al. 2008b; Shvedova et al. 2008c; Simeonova 2009; Warheit et al. 2004) outlines the growing concerns regarding the toxicity of CNTs. Recent review papers (Ema et al. 2016; Gao et al. 2016; Kuempel et al. 2016; Ong et al. 2016; Pacurari et al. 2016; Siegrist et al. 2014; Vietti et al. 2016) provide an excellent overview of the current knowledge regarding adverse health effects of single-walled carbon nanotubes (SWCNTs) and multi-walled carbon nanotubes (MWCNTs). The Organization for Economic Cooperation and Development (OECD) has recently published comprehensive summaries of the environmental health and safety aspects of both MWCNTs (OECD 2016a) and SWCNTs (OECD 2016b). Rodent studies have found an acute inflammatory response, granulomas, fibrosis, and decreased rates of respiration and bacterial clearance from the lungs. Importantly, the National Institute for Occupational Safety and Health (NIOSH) (NIOSH 2013) concluded that “...in animal studies where CNTs were compared with other known fibrogenic materials (e.g., silica, asbestos, ultrafine carbon black), the CNTs were of similar or greater potency, and the effects, including fibrosis, developed soon after exposure and persisted." Adverse impacts on other organ systems, including cardiac inflammation, have also been found (NIOSH 2013). Such a wide range of acute and chronic health effects associated with CNTs, particularly the strong fibrogenic potential, are reason enough for concern - but even more serious concerns have arisen. Almost twenty years ago, the morphological similarity between CNTs and other fibrous materials, such as asbestos, raised concerns as to whether exposure to CNTs could cause lung cancer and/or mesothelioma (Service 1998). Research followed, and two groups observed asbestos-like effects in short-term bioassays when MWCNTs were injected intraperitoneally into mice (Poland et al. 
91 2008; Takagi et al. 2008); subsequently, Ryman-Rasmussen et al. (Ryman-Rasmussen et al.

92 2009)found that inhaled MWCNTs reached the subpleura of mice and Mercer et al. (Mercer et al. 2010) found that they penetrated the intrapleural space. Additional research has for the most 94 part confirmed the results of the first studies (Muller et al. 2009; Nagai et al. 2011; Rittinghausen et al. 2014; Schinwald et al. 2012), while others were negative (Muller et al. 2009).

Recently, the International Agency for Research on Cancer (IARC) reviewed the available toxicological studies and classified certain MWCNTs as a Group 2B carcinogen, where Group 2B is defined as "possibly carcinogenic to humans" (Grosse et al. 2014; IARC 2017; Kuempel et al. 2016). IARC based its classification on the Poland and Takagi rodent studies, which used a particular MWCNT designated "MWCNT-7," and its classification applies only to this particular product. Specifically, IARC found that "inhalation of MWCNT-7 promoted bronchioloalveolar adenoma and carcinoma in male mice" and "MWCNT-7 caused peritoneal mesotheliomas in 103 male and female rats in one intraperitoneal injection study and one intrascrotal injection study, and in male p53+/- mice in two intraperitoneal injection studies"(Grosse et al. 2014). Although rodents were exposed by routes other than inhalation, IARC referenced Mercer et al. (Mercer et al. 2010) to conclude that "mechanistic and other data in rodents provided evidence of trans location of three types of MWCNTs (including MWCNT-7) to the pleura." The Rittinghausen paper (Rittinghausen et al. 2014) was published after the IARC review occurred, and found that four different MWCNTs induced mesothelioma in 40-98\% of the rats tested.

All evidence for adverse health effects is based on animal toxicity studies; no case reports or epidemiological studies of CNT-specifically exposed workers have been published. Oberdörster, et al. (Oberdörster et al. 2015) discuss in detail the difficulties in conducting a proper animal inhalation study for CNTs, including e.g. the use of different delivery techniques (instillation, 
114 aspiration, inhalation), high doses, high dose rates, pretreatment with dispersants, poor 115 distribution throughout the respiratory tract, etc. These difficulties and differences between 116 studies make it very difficult to translate results of rodent studies to levels of exposure likely to 117 cause adverse health effects in humans. However, the animal studies, taken together, seem to 118 indicate that at least some MWCNTs cause the same three major diseases associated with 119 asbestos use (pulmonary fibrosis, lung cancer and mesothelioma) and in fact may be a more 120 potent cause of these very serious diseases. The history of asbestos exposure and disease is well121 known, and leads to the obvious questions as to whether the occupational and environmental 122 health community can take proper action to prevent another similar pattern of exposure and 123 disease development. Such questions are ones of broad public health policy, with implications 124 well beyond occupational hygiene. We believe that the occupational and environmental health 125 community in particular must act proactively to ensure that workers and members of the public 126 are not needlessly exposed to what may in the future be confirmed as a human carcinogen. The 127 strong animal evidence of toxicity requires that the occupational hygiene community develop 128 strategies for reducing or eliminating worker exposures to CNTs.

129 This commentary focuses on the issue of setting appropriate occupational exposure levels 130 (OELs) for CNTs, although many issues must be addressed, including exposure assessment 131 methodologies and effective exposure control strategies. We first describe the OELs suggested 132 by government agencies and companies; at this time there are no regulatory OELs specific to 133 CNTs. We then discuss important issues that must be addressed in the setting of an OEL for 134 CNTs, including the more fundamental question about the appropriateness of OELs for 135 suspected carcinogens. We close with some recommendations for actions we believe should be 136 taken in the near future to address this important issue. 


\section{Recommended OELs}

In response to the adverse health effects found in animal studies, several governmental 140 agencies, and one private company, have published occupational exposure limits for CNTs. 141 These are briefly reviewed here.

142 The British Standards Institute (BSI) in 2007 recommended a "benchmark" CNT OEL of

1430.01 fibers $/ \mathrm{cm}^{3}\left(\mathrm{f} / \mathrm{cm}^{3}\right)$, as measured by scanning or transmission electron microscopy (BSI 144 2007). This level is equivalent to the most rigorous exposure limit in Britain for asbestos, i.e., the 145 highest concentration that can be present inside a space after asbestos removal activities (also 146 called the clearance limit, this is the same limit as used by the US EPA for this activity).

147 The German company Bayer Schering Pharmaceuticals studied the toxicity of their 148 MWCNTs, called Baytubes. They concluded that exposure is unlikely to lead to mesothelioma or 149 other chronic conditions because Baytubes are flexible, leading to the formation of relatively 150 large assemblages, or "bird's nests" of tubes. They set a company OEL for Baytubes of 50 $151 \mu \mathrm{g} / \mathrm{m}^{3}$, based on measured acute toxicity in rats (Pauluhn 2010). Pauluhn stated that their 152 measurements of Baytube mass concentration were made "utilizing cobalt [a catalyst used in 153 Baytube manufacturing] as a tracer (in order to distinguish carbonaceous background dust from 154 Baytubes)" but no more details of the measurement method were provided.

155 The Japanese National Institute of Advanced Industrial Science and Technology (AIST) 156 derived OELs of $30 \mu \mathrm{g} / \mathrm{m}^{3}$ for SWCNTs and $80 \mu \mathrm{g} / \mathrm{m}^{3}$ for MWCNTs (Nakanishi 2011), based on 157 studies supported by the New Energy and Industrial Technology Development Organization 
158 (NEDO) of Japan. These limits were based on no observed effect levels (NOELs) calculated for 159 non-carcinogenic effects.

The Swiss Accident Insurance Funds (SUVA) addressed carbon nanotubes and fibers in the 161 Swiss 2011 occupational exposure limit list (SUVA 2011). The document highlighted the 162 structural similarities of CNTs and CNFs to other fibers such as asbestos and noted that these 163 materials lead to inflammation. The document specifically mentioned that studies done with long 164 rigid MWCNTs suggest that they may be carcinogenic; consequently, they recommended an 165 exposure limit of $0.01 \mathrm{f} / \mathrm{cm}^{3}$ for CNTs and CNFs. This limit corresponds to their threshold value 166 for asbestos fibers and remains in the latest (2015) edition of the occupational exposure limit list. levels for evaluating engineered nanoparticle (ENP) exposures, based on what IFA considers to 169 be likely predictors of ENP toxicity, i.e., size, shape, density and biopersistence. Four groups are 170 defined, each with a "nano reference value (NRV)." Group 1 consists of "rigid, biopersistent 171 nanofibers for which effects similar to those of asbestos are not excluded" (e.g., CNTs) with a $172 \mathrm{NRV}$ of $0.01 \mathrm{f} / \mathrm{cm}^{3}$ (the same as the BSI recommendation for CNTs and asbestos) (van 173 Broekhuizen and Dorbeck-Jung 2013). It is clear that the NRVs are meant to be differentiated 174 from actual health-based OELs, and are to be used as interim exposure guidelines until OELs can 175 be developed (van Broekhuizen et al. 2012).

176 After much discussion of an earlier draft, in 2013 NIOSH published Current Intelligence 177 Bulletin (CIB) with a recommended exposure limit (REL) of $1 \mu \mathrm{g} / \mathrm{m}^{3}$ of elemental carbon (EC) 178 (NIOSH 2013). This limit is based on the limit of quantitation (LOQ) of Method 5040, titled 179 "Diesel Particulate Matter (as Elemental Carbon)" (NIOSH 2003). They calculate that the LOQ 180 "can be obtained for an 8-hr respirable sample collected on a $25-\mathrm{mm}$ filter at a flow rate of 4 
181 liters per minute (lpm)." Regarding health effects, for a 45-year lifetime exposure at the REL, 182 NIOSH developed "maximum likelihood estimates" of $2.4-33 \%$ for "minimal lung effects" and $183 \quad 0.23-10 \%$ for "slight or mild lung effects" as. The CIB concluded that "NIOSH does not 184 consider a 10\% estimated excess risk over a working lifetime to be acceptable for these early185 stage lung effects, and the REL is set at the optimal limit of quantification (LOQ) of the 186 analytical method carbon (NIOSH method 5040).”

187 Carcinogenic potential was not considered in setting the REL. "NIOSH has determined that 188 the best data to use for a quantitative risk assessment and as basis for a recommended exposure 189 limit (REL) are the nonmalignant pulmonary data from the CNT animal studies. At present, data 190 on cancer and cardiovascular effects are not adequate for a quantitative risk assessment of 191 inhalation exposure" (NIOSH 2013).

192 To summarize, various entities have recommended both mass-based and number-based OELs 193 for CNTs, as shown in Table 1. The number-based recommendations all are consistent with the 194 strictest asbestos OEL of $0.01 \mathrm{f} / \mathrm{cm}^{3}$, whereas the mass-based recommendations range from 1 $19580 \mu \mathrm{g} / \mathrm{m}^{3}$.

197 Advantages and Disadvantages of a Mass-Based OEL for CNTs

198 AIST, Bayer and NIOSH developed mass-based CNT OELs for some very good reasons. 199 One advantage, as discussed above, is that the use of mass concentration correlates well with 200 non-carcinogenic end-points in animal toxicity studies. The primary benefit of this approach, 201 however, is that it uses classic occupational hygiene measurement methods and metrics. Any 202 OEL loses most of its utility if there are no methods to measure worker exposure for comparison 
203 to the standard. For example, the NIOSH REL requires the use of readily-available air sampling

204 equipment and a validated sample analysis method that can be performed by many laboratories at

205 as reasonable price. Thus, any reasonably-proficient field occupational hygienist can collect a

206 valid sample and compare it to the REL. This advantage makes a compelling reason for using

207 this approach.

208 There are, however, several concerns with using a mass-based OEL for CNTs. First, the risks

209 of developing the most serious adverse health effects, i.e., fibrosis, lung cancer and

210 mesothelioma, are a function not of the mass of CNTs inhaled but on the number of

211 appropriately-sized fibers inhaled and subsequently depositing in alveoli. Since the mass of any

212 individual CNT can vary greatly, a given mass concentration can have a widely ranging number

213 concentration, so that a mass-based OEL does not correlate well with the property of interest,

214 number. Second, an air sample is likely to collect both CNTs and other particles, but the

215 available analytical methods cannot directly measure the mass of CNTs collected. Available

216 methods rely on a surrogate of CNT mass, such as cobalt for Baytubes and elemental carbon for

217 NIOSH. While it is true that CNTs consist largely of elemental carbon, there may other sources

218 of elemental carbon in the workplace, such as carbon soot formed by incomplete tube formation

219 in a CNT furnace, or diesel exhaust from fork lift trucks in a factory incorporating CNTs into a

220 product.

221 A third concern with a mass-based OEL is that the actual values proposed correspond to

222 number concentrations that can be much higher than asbestos OELs because they are based

223 either on acute health effects for a specific tested CNT (the AIST OEL of $80 \mu \mathrm{g} / \mathrm{m}^{3}$ ) or on

224 available analytical methods (the NIOSH REL of $1 \mu \mathrm{g} / \mathrm{m}^{3}$ ). The issue was discussed by Schulte,

225 et al. (Schulte et al. 2012), who compare fiber number concentrations for fibers of different 
226 dimensions to a mass concentration of $7 \mu \mathrm{g} / \mathrm{m}^{3}$ (this was the original proposed REL of NIOSH).

227 Adjusting their conversions to $1 \mu \mathrm{g} / \mathrm{m}^{3}$, this corresponds to 0.01 fibers $/ \mathrm{cm}^{3}$ for a very large fiber

$228(2,110 \mathrm{~nm}$ diameter $\mathrm{x} 10,000 \mathrm{~nm}$ length $)$ and 300,000 fibers $/ \mathrm{cm}^{3}$ for a very small fiber $(2 \mathrm{~nm} \mathrm{x}$ $229500 \mathrm{~nm}$ ). These fiber concentrations range from lower than the asbestos PEL of $0.1 \mathrm{f} / \mathrm{cm}^{3}$ to 230 much higher than the PEL (OSHA 1994).

\section{Advantages and Disadvantages of a Number-Based OEL for CNTs}

The use of a fiber number-based OEL also presents distinct advantages and disadvantages.

234 The primary advantage is that the risk of developing the serious chronic diseases that have been associated with CNT exposure in animal studies - fibrosis, lung cancer, and mesothelioma - are

236 all a function of the number of fibers deposited in the alveolar region of the lung, not the mass. It

237 is for this reason that all asbestos OELs are given in $\mathrm{f} / \mathrm{cm}^{3}$. The primary disadvantage of a 238 number-based OEL is that it is difficult and costly to obtain exposure measurements. Breathing239 zone asbestos concentrations are measured by passing the sampled air through a cellulose ester 240 membrane filter and examining the filter with a phase contrast optical microscope. 241 Unfortunately, CNTs are too small to be seen by an optical microscope, and electron microscopy 242 must be used, increasing the cost of analysis by at least an order of magnitude. Direct-reading 243 particle counters can also be used, but they are expensive and count all particles, not just fibers. 244 We will return to this measurement conundrum in the Recommendations section. 
A one-size-fits-all OEL is unlikely to adequately protect workers because the literature 248 suggests that there may be important differences in toxicological response among types of CNTs. 249 In various studies, single wall carbon nanotubes (SWCNTs) have not been found to cause 250 mesothelioma (Kuempel et al. 2016). In addition, thin $(\mathrm{d}<15 \mathrm{~nm})$ and short $[\mathrm{L}<1 \mu \mathrm{m}$ 251 according to Muller et al. (Muller et al. 2009) and $\mathrm{L}<5 \mu \mathrm{m}$ according to Schinwald et al. 252 (Schinwald et al. 2012) MWCNTs do not cause mesothelioma. SWCNTs and thin MWCNTs, 253 when examined microscopically, tend to curl and form bundles which are not fiber-shaped. 254 Presumably, this shape enhances their clearance from the pulmonary region by phagocytosis. 255 Likewise, very short MWCNTs may be cleared effectively by macrophages (Rittinghausen et al. 256 2014). As an added complication, Nagai et al. (Nagai et al. 2011) found that very thick 257 MWCNTs $(\mathrm{d}>150 \mathrm{~nm})$ were less carcinogenic than thinner ones; however, there is evidence 258 that such large-diameter tubes are not important commercially.

259 The absence of mesothelioma initiation when short tubes are administered to test animals 260 suggests the possibility of treating pristine tubes to shorten them. Ali-Boucetta et al. (Ali261 Boucetta et al. 2013) used two different reactions to functionalize pristine long MWCNTs and 262 found that one reaction (functionalization with TEG chains using the 1,3-dipolar cycloaddition 263 reaction) led to a reduction of the effective length of the MWCNTs, while a second reaction 264 (functionalization with octyl chains following the Billups reaction) did not. These results suggest 265 that functionalization needs much further research, and in any case must be used with great care. 266 For example, procedures applied in the laboratory that shorten $100 \%$ of the tubes may have 267 lower efficiency when applied at an industrial scale. In addition, many industrial processes may 268 require the use of longer tubes, eliminating this option from consideration. 
Another approach that may be effective in certain applications where the MWCNTs are

270 dispersed in water is to coat them with a surfactant. Wang et al. (Wang et al. 2012) found that

271 dispersing MWCNTs in Pluronic F 108, a difunctional block copolymer surfactant, reduced

272 fibrogenic response by reducing damage to the lysosomal membrane.

273 In any case, MWCNTs subject to any such treatments could never be considered completely

274 safe, since the possible exposure of the workers manufacturing the pristine tubes and

275 functionalizing them would have to be considered. For example, to coat CNTs with a surfactant,

276 the dry tubes would have to be dispersed into the water and surfactant, a potentially hazardous

277 operation.

278

279 Agglomerates vs. Individual Fibers

280 Another significant complication that is not addressed by using a mass-based OEL is that 281 airborne CNTs may exist as individual fibers or as agglomerates or bundles of fibers. The state 282 of agglomeration can influence both the respiratory deposition pattern of the inhaled fibers and 283 the toxicological response. Researchers have found varied changes in toxicity when CNTs 284 agglomerate. For example, Gao et al. (Gao et al. 2016) found that "it clearly appears that 285 aggregation of SWCNTs should be avoided and that nanotube individualization is a key 286 parameter to minimize cellular toxicity." Wick et al. (Wick et al. 2007) found that agglomerated 287 MWCNTs were more toxic than well-dispersed ones. On the other hand, end effects that depend 288 on the fibrotic nature of CNTs (fibrosis and mesothelioma) should presumably be ameliorated by 289 the formation of non-fiber-shaped agglomerates (Kuempel et al. 2016). Song et al. (Song et al. 290 2016) summarized the current muddled state of the research on this topic thus: "more efforts 291 should be paid to study the biological effects of agglomeration." In any case, a significant 
292 shortcoming of mass-based OELs is that the state of agglomeration in the sample would not be 293 known.

294 From an occupational hygiene viewpoint, agglomeration complicates the use of number295 based OELs. Counting schemes need to be developed to address this issue; it is likely that an 296 approach similar to that used for high aspect ratio particles such as bundles of asbestos fibers, 297 where clearly-identified fiber "ends" in fiber bundles are counted, may be needed. NIOSH in 2982016 published a draft analytical method titled "Analysis of Carbon Nanotubes and Nanofibers 299 on Mixed Cellulose Ester Filters by Transmission Electron Microscopy" (Birch et al. 2016), 300 which was a modification to NIOSH NMAM 7402, asbestos by TEM (NIOSH 1994). It is an 301 initial attempt to develop an approach in the United States.

\section{Actions by Other Government Agencies}

304 The U.S. Environmental Protection Agency (EPA) regulates CNTs under the Toxics Substance 305 Control Act (TSCA). CNTs were designated as a material requiring a premanufacture 306 notification (PMN), and, as an example, in September, 2017 the EPA issued a significant new 307 use rule (SNUR) for a specific CNTs used in filtration media (EPA 2017). The company308 specific SNUR requires the use of protective clothing and NIOSH-approved respirators where 309 there is as potential for exposure, processing and use of only those quantities specified in the 310 consent order, processing only as a aqueous slurry, wet form, or "contained" dry form, prohibits 311 release of CNTs to surface waters, and requires disposal to be done only by landfill or 312 incineration. The SNUR's restrictions on manufacture, processing, distribution in commerce, 313 and disposal will remain in effect until the results of recommended testing is completed (2-year 
314 inhalation bioassay; daphnid chronic; and algal toxicity). Such actions by EPA, done in consultation with NIOSH and OSHA, serve as an interim approach to worker exposure while awaiting the results of recommended toxicity testing.

The European Union's law regarding Registration, Evaluation, Authorization and Restriction of Chemical substances (REACH), which entered into force on June 1, 2007 (Commission of the European 2007), may also offer some protection to workers potentially exposed to CNTs. TSCA and REACH differ greatly in their approaches to regulating chemical health and safety, and a detailed comparison of the two approaches is beyond the scope of this paper. Readers interested in such a comparison are referred to Chapter 11 of the textbook by Ellenbecker and Tsai (Ellenbecker and Tsai 2015). Briefly, it is fair to say that REACH does not provide the detailed performance standards specified in a SNUR, but rather requires manufacturers to proactively ensure that their products are manufactured and used safely. In addition, the European Commission has promulgated a recommended "code of conduct for responsible nanosciences and nanotechnologies (N\&N) research" (EC 2008). Key elements of the code of conduct include:

N\&N research activities should be safe, ethical and contribute to sustainable development serving the sustainability objectives of the Community as well as contributing to the United Nations' Millennium Development Goals. They should not harm or create a biological, physical or moral threat to people, animals, plants or the environment, at present or in the future.

$\mathrm{N} \& \mathrm{~N}$ research activities should be conducted in accordance with the precautionary principle, anticipating potential environmental, health and safety impacts of N\&N outcomes and taking due precautions, proportional to the level of protection, while encouraging progress for the benefit of society and the environment.

Governance of N\&N research activities should be guided by the principles of openness to all stakeholders, transparency and respect for the legitimate right of 
access to information. It should allow the participation in decision-making processes of all stakeholders involved in or concerned by N\&N research activities.

The EC recommends:

That Member States encourage the voluntary adoption of the Code of Conduct by relevant national and regional authorities, employers and research funding bodies, researchers, and any individual or civil society organization involved or interested in $N \& N$ research and endeavor to undertake the necessary steps to ensure that they contribute to developing and maintaining a supportive research environment, conducive to the safe, ethical and effective development of the N\&N potential.

\section{Other Considerations}

Other important CNT occupational hygiene issues, such as exposure assessment and control, depend to some extent on decisions made about appropriate OELs. Methods used to evaluate exposure will differ greatly for a mass-based OEL and a number-based OEL. An advantage of the mass-based OELs when compared to a number-based OEL is that personal samples can be collected and analyzed using readily-available and well-understood equipment and techniques. In contrast, measuring the number concentration and size distribution of nanometer-sized fibers requires expensive, specialized equipment and operator skill and is limited at this time to area samples, with no agreed-upon technique to be used.

The measurement of a very low number concentration of MWCNTs of a certain size will likely require the development and validation of a new method based on transmission electron 
microscopy. However, any CNT OEL is likely to require some form of electron microscopy in

367 order to ensure that what is being sampled and analyzed actually contains CNTs. The CIB further

368 recommends that EC and electron microscope samples be collected in parallel and that for each

369 EC sample where the concentration that exceeds the NIOSH REL, the electron microscope 370 sample should be analyzed to confirm that the EC actually came from CNTs.

371 All of the proposed OELs represent very low levels of exposure, and effective administrative 372 and engineering controls will be required to reduce exposures to acceptable levels. Research has 373 demonstrated that standard control practices, such as local exhaust ventilation and high374 efficiency particulate air (HEPA) filtration, when applied with care, can effectively control 375 nanoparticle exposures to minimal level (Golanski et al. 2010; Tsai et al. 2009a; Tsai et al. 376 2008b; Tsai et al. 2012), and publications on best practices are widely available (BSI 2007; DOE 377 2008; NCI 2008; NIOSH 2012; Wood 2000). Large MWCNTs will require, however, the highest 378 level of controls to reduce exposures to a concentration such as the BSI benchmark. 379 Sophisticated containment systems, such as those used by the pharmaceutical industry (Wood 380 2000), may be required.

381 The recent IARC classification for MWCNT-7 raises a more significant question about 382 establishing OELs, namely, should we even be issuing OELs for carcinogens or suspected 383 carcinogen where the evidence is clear that the "best" exposure limit is no exposure.

384 Some might argue that the "lowest possible level of exposure" approach be limited to IARC 385 1A confirmed human carcinogens and thus is overly strict for MWCNTs, an IARC 2B suspect 386 human carcinogen (Grosse et al. 2014; IARC 2017; Kuempel et al. 2016). However, the 1A 387 designation is only given to substances with sufficient positive epidemiologic evidence of an 388 association between the substance and the cancer. Effectively, every new $1 \mathrm{~A}$ designation 
represents a case of evident exposure to workers, since in every case there is evidence of toxicity 390 before the 1A designation and, in spite of that evidence, exposures were allowed sufficient to 391 lead to a statistically significant level of cancer. Recognizing this, the American Conference of 392 Governmental Industrial Hygienists states that for suspected human carcinogens, "worker 393 exposure by all routes should be carefully controlled to levels as low as possible..." (ACGIH 394 2012) Our goal should be that there is never a positive epidemiology study for MWCNTs (or any 395 other engineered nanoparticle, for that matter).

Rather than presuming that we can control workplace exposures to CNTs, especially those 397 with evidence of carcinogenicity, there is a need to redirect technological developments that are 398 venturing down unsafe paths. At a minimum, each potential use of MWCNTs must first undergo 399 a rigorous analysis of the potential benefits versus the possible risks. Two hypothetical examples 400 may illustrate this point. The first is the incorporation of MWCNTs into tennis racquet frames. 401 This would require the use of relatively large amounts of dry MWCNTs being mixed with the 402 polymer in an extruder, with high potential for exposure to workers (Tsai et al. 2008a) and would 403 offer minor benefits to society. The second example is the use of MWCNTs as advanced 404 memory storage devices in electronics. The manufacturing process would use minimal amounts 405 of MWCNTs suspended in water, with minimal potential for worker exposure or environmental 406 release, while potential benefits to society are very large. The first example may fail the risk407 benefit test, while the second may pass it.

408 Such an approach is consistent with the European Union's 2004 workplace carcinogen 409 directive (EU 2004), which requires that employers replace the use of carcinogens with less 410 dangerous substitutes wherever feasible. History has shown us too many public and occupational 
411 health tragedies where society allowed the proliferation in use of suspected carcinogens by

412 industry while scientists waited for evidence in humans to mount. Is the risk worth the wait?

414 Recommendations

415 In response to the concerns discussed above, the following specific actions are

416 recommended:

\section{Intensify outreach to employers and employees}

418 Industry and the research community are in great need of guidance concerning worker 419 exposures to CNTs. Some studies have found elevated exposures in facilities that manufacture 420 CNTs (Baron et al. 2003; Bello et al. 2008; Dahm et al. 2011; Han et al. 2008; Lee et al. 2010; 421 Tsai et al. 2009b) and those that incorporate CNTs into devices (Bello et al. 2009; Cena and 422 Peters 2011; Dahm et al. 2011). Unfortunately, these studies did not evaluate exposures in plants 423 or laboratories subject to TSCA or $\mathrm{REACH}$, so it is difficult at this time to assess either 424 legislations impact on protecting worker health. It is likely that both approaches are having a 425 positive effect on reducing worker exposures in the absence of specific exposure limits, but it is 426 also likely that exposures have not been reduced to the lowest possible level, as would be 427 required for any CNTs that are in fact carcinogens.

428 It has been our experience that many employers likely have not yet measured their workers' 429 exposures, and those that have made measurements likely are unsure whether their exposures 430 should be of concern. It should be of concern, however, if workers are being exposed to what 431 likely is a potent carcinogen. It is absolutely imperative that the occupational hygiene community 
432 do all it can to ensure that exposure to CNTs is being effectively controlled in workplaces, so

433 that life threatening diseases won't develop in humans.

434 Provide more nuanced CNT OELs to industry

435

436

437

438

439

440

441

442

443

444

445

446

447

448

449

450

451

452

453

454

The mass-based OELs are meant to be protective against the non-carcinogenic adverse health effects from exposure. Referring to CNTs, we should consider 1) what OEL is appropriate to be protective against cancer, remembering that 2) the number concentration corresponding to a mass-based OEL is highly variable depending on the fiber size (Schulte et al. 2012).

Based on the published studies reviewed above, a mass-based OEL may be appropriate for SWCNTs and short MWCNTs, based on the lack of current evidence for their carcinogenicity. This approach may prove to be short-sighted, however, if future toxicology and/or epidemiology studies prove otherwise, and is somewhat similar to the seemingly endless debates over the relative carcinogenicity of different asbestos fiber types, lengths and diameters. Although for a period of time the ACGIH had different TLVs for different asbestos fiber types, the occupational hygiene community has in effect made a collective decision to avoid these arguments with respect to asbestos and to issue a single OEL for all asbestos types (but not all fiber lengths). Whether or not this is the proper approach for CNTs must be carefully considered.

In any case, the precautionary approach of reducing exposures to the lowest practical level may need to be applied to long MWCNTs $(\mathrm{d}>15 \mathrm{~nm}, \mathrm{~L}>2 \mu \mathrm{m})$, and, thus they may specifically be exempt from any mass-based CNT OEL. Given the uncertainties in health risk, exposure to all CNTs should be controlled to the lowest possible level. Any discussion of a CNT OEL should include statements that long MWCNTs should not be used unless absolutely necessary, according to current toxicological evidence discussed above, and then if and only if engineering and administrative controls are available to reduce exposure to the lowest possible level. 
455 Although workers manufacturing such CNTs and incorporating them into devices are at the most 456 risk, this precautionary approach shall be applied to all phases of a product's life.

\section{Broaden the discussion}

458 It is critical that decisions regarding the setting of OELs for CNTs involve all parties that 459 have a role in this process. At a minimum in the United States, this should include NIOSH, 460 OSHA, The American Conference of Governmental Hygienists (ACGIH), the American 461 Industrial Hygiene Association (AIHA), and representatives from industry and labor. 462 Appropriate representatives from other countries and areas involved in CNT research and 463 manufacturing (European Union, China, Taiwan, Japan, Korea, etc.) should be included for a 464 global perspective. The goals of these discussions should be 1) the setting of a consensus OEL

465 (or OELs) for CNTs, and 2) agreement on a measurement method to be used for evaluating 466 exposures for comparison to the OEL. Meeting these goals likely will require further research, 467 discussed below.

\section{Encourage further research}

469 CNTs often are found as large bundles. However, the stability of these bundles is not well 470 understood. Methods to study the stability of such bundles need to be developed. This method 471 development would be done ideally in parallel with studies on the toxicity of such bundles so 472 that a decision can be made whether bundles should be treated as the sum of many individual 473 fibers or if only the number of free fibers need to be taken into account by a fiber count OEL.

474 Until such a method is developed and tested, the proper procedure will remain a challenge. A 475 conservative approach is to assume that individual fibers can be released into the surrounding 476 tissue after such a bundle was deposited in the lungs; this would lead to the counting of 477 individual fibers inside bundles. 
Research is needed into the development of a reliable, cost-effective method to measure

479 exposure to CNTs. Such a method likely would involve the direct collection of an air sample onto a filter or TEM grid, followed by a standardized fiber counting procedure, or a direct reading device that can measure fiber mass and/or volume. Research is needed in both of these areas. Several different techniques are available to directly deposit particles on TEM grids (diffusion, electrostatic and thermal deposition) and the method that best deposits particles of all relevant sizes should be determined. With regard to counting, it would be highly desirable to develop an automated method to scan grids and identify, count and size fibers, since manual counting and sizing is a very costly procedure.

\section{Additional recommendations}

CNT Safety Data Sheets, which to date have been seriously deficient (Eastlake et al. 2012), should include sufficient information to communicate the potential hazards discussed in this article. Efforts to prevent release to the environment should also be implemented. Information should also be provided to handlers of wastes containing these materials, including but not limited to personal protective equipment (respirator cartridges, disposable lab coats, gloves, etc.), cleaning wipes, and used air filters from exhaust systems. Manufacturers incorporating any CNT into products should consider appropriate warnings to users, and all products incorporating possibly a more toxic type, e.g. long MWCNTs, should include appropriate warning labels.

CNTs, of course, are only one category among many other nanomaterials either in current use or undergoing research for future use. It is likely that OELs will be needed for many of these materials; some of the difficult issues discussed here are unique to CNTS due to their being fibers, but the use of mass metrics will always present difficulties for nanomaterials. Precisely because they are so small, nanoparticle mass concentrations are typically very low, and masked 
501 by the presence of other, larger particles in the same sample. Thus, we can expect significant 502 difficulties in setting all OELs for nanomaterials. Nonetheless they will be needed, and the 503 occupational health community needs to face this challenge head on.

\section{Conclusion}

The association between asbestos exposure and mesothelioma was established more than 507 fifty years ago, but the mesothelioma epidemic continues. An estimated 107,000 people 508 worldwide die from this disease every year; many of those now dying from mesothelioma are

509 family members of the worker who had the primary exposure (Markowitz 2015). It is imperative 510 that this disaster not be seen with other high aspect ratio particles such as CNTs. Strong action 511 needs to be taken to minimize exposures to CNTs type 7 specifically and CNTs in general, and 512 any CNT OEL should be consistent with the need to minimize exposures. The conclusions of 513 Schulte, et al., (Schulte et al. 2012) are worth repeating:

514 In the evolution of human civilizations, learning from the history and not repeating it has been a key guiding principle. Society can learn from how asbestos was inappropriately considered and not make the same mistake with CNTs. It is possible to safely realize the benefits of CNTs, but it will require rigorous and timely actions. The time to act is now.

\section{$519 \quad$ Funding}

520 No funding was received in connection with this manuscript.

\section{Conflict of Interest}

522 The authors declare that they have no conflict of interest. 
ACGIH (2012) 2012 TLVs and BEls - based on the documentation of the threshold limit values for chemical substances and physical agents \& biological exposure indices. Cincinnati, $\mathrm{OH}$ : American Conference of Governmental Industrial Hygienists.

Ali-Boucetta H, Nunes A, Sainz R, Herrero MA, Tian B, Prato M, Bianco A, Kostarelos K (2013) Asbestoslike pathogenicity of long carbon nanotubes alleviated by chemical functionalization. Angewandte Chemie (International Ed.In English) 52(8):2274-2278.

Baron PA, Maynard AD, Foley M (2003) Evaluation of aerosol release during the handling of unrefined single walled carbon nanotube material. Cincinnati: Department of Health and Human Services, Centers for Disease Control and Prevention, National Institute for Occupational Safety and Health. NIOSH DART-02-191 Rev.1.1.

Bello D, Hart AJ, Ahn K, Hallock M, Yamamoto N, Garcia EJ, Ellenbecker MJ, Wardle BL (2008) Particle exposure levels during CVD growth and subsequent handling of vertically-aligned carbon nanotube films. Carbon 46:974-981.

Bello D, Wardle BL, Yamamoto M, Guzman de Villoria R, Garcia EJ, Hart AJ, Ahn K, Ellenbecker MJ, Hallock M (2009) Exposure to nanoscale particles and fibers during machining of hybrid advanced composites containing carbon nanotubes. J Nanopart Res 11(1):231-249.

Birch EM, Wang C, Fernback JE, Feeng HA, Birch QT, Dozier AK (2016) Draft Report, Analysis of Carbon Nanotubes and Nanofibers on Mixed Cellulose Ester Filters by Transmission Electron Microscopy. Cincinnati: Department of Health and Human Services, Centers for Disease Control and Prevention, National Institute for Occupational Safety and Health.

Boxall AB, Tiede $K$, Chaudhry Q (2007) Engineered nanomaterials in soils and water: how do they behave and could they pose a risk to human health? Nanomed (Lond) 2(6):919-927.

BSI (2007) Nanotechnologies - Part 2: Guide to safe handling and disposal of manufactured nanomaterials. British Standards Institute. Report No. 9780580608322.

Cena L, Peters T (2011) Characterization and Control of Airborne Particles Emitted During Production of Epoxy/Carbon Nanotube Nanocomposites. J Occup Environ Hyg 8:86-92.

Commission of the European C. 2007. REACH. Commission of the European Communities.

Dahm M, Evans D, Schubauer-Berigan M, Birch M, Fernback J (2011) Occupational Exposure Assessment in Carbon Nanotube and Nanofiber Primary and Secondary Manufacturers. Ann Occup Hyg 56(5):542-556.

DOE (2008) Nanoscale Science Research Center: approach to nanomaterial ES\&H, Rev.3a. Department of Energy.

Donaldson K, Aitken R, Tran L, Stone V, Duffin R, Forrest G, Alexander A (2006) Carbon nanotubes: a review of their properties in relation to pulmonary toxicology and workplace safety. Toxicol Sci 92(1):5-22.

Eastlake A, Hodson L, Geraci C, Crawford C (2012) A critical evaluation of material safety data sheets (MSDSs) for engineered nanomaterials. Chem Health Saf 19(5):1-8.

EC (2008) Code of conduct for responsible nanosciences and nanotechnologies research. European Commission.

Ellenbecker MJ, Tsai SJ (2015) Health and Safety Considerations for Working with Engineered Nanoparticles. Wiley Interscience.

Ema M, Gamo M, Honda K (2016) A review of toxicity studies of single-walled carbon nanotubes in laboratory animals. Reg Toxic Pharmac 74:22.

EPA (2017) Significant New Use Rules on Certain Chemical Substances. Washington D.C.: Environmental Protetion Agency. 
602

603

604

605

606

607

608

609

610

EU (2004) On the protection of workers from the risks related to exposure to carcinogens or mutagens at work. European Union. Directive 2004/37/EC.

Gao Z, Varela JA, Groc L, Lounis B, Cognet L (2016) Toward the suppression of cellular toxicity from single-walled carbon nanotubes. Biomater Sci 4(2):230-244.

Golanski L, Guiot A, Tardif F (2010) Experimental evaluation of individual protection devices against different types of nanoaerosols: graphite, TiO2, and Pt. J Nanopart Res 12:83-89.

Grosse Y, Loomis D, Guyton KZ, Laugy-Secretan B, El Ghissassi F, Bouvard V, Bernbrahim-Tallea L, Guha N, Scoccianti C, Mattock H, Straiff K (2014) Carcinogenicity of fluoro-edenite, silicon carbide fibres and whiskers, and carbon nanotubes. Lancet Oncol 15(13):1427-1428.

Han JH, Lee EJ, Lee JH, So KP, Lee YH, Bae GN, Lee SB, Ji JH, Cho MH, Yu J (2008) Monitoring multiwalled carbon nanotube exposure in carbon nanotube research facility. Inhal Toxicol 20(8):741-749.

IARC (2017) Some Nanomaterials and Some Fibres. Lyon: International Agency for Research on Cancer. Monographs on the Evaluation of Carcinogenic Risks to Humans, Vol. 111.

Kisin ER, Murray AR, Keane MJ, Shi XC, Schwegler-Berry D, Gorelik O, Arepalli S, Castranova V, Wallace WE, Kagan VE, Shvedova AA (2007) Single-walled carbon nanotubes: geno- and cytotoxic effects in lung fibroblast V79 cells. J Toxicol Environ Health A 70(24):2071-2079.

Kisin ER, Murray AR, Sargent L, Lowry D, Chirila M, Siegrist KJ, Schwegler-Berry D, Leonard S, Castranova V, Fadeel B, Kagan VE, Shvedova AA (2011) Genotoxicity of carbon nanofibers: Are they potentially more or less dangerous than carbon nanotubes or asbestos? Toxicol Appl Pharmacol 252(1):1-10.

Kuempel ED, Jaurand M, Møller P, Morimoto Y, Kobayashi N, Pinkerton KE, Sargent LM, Vermeulen RCH, Fubini B, Kane AB (2016) Evaluating the mechanistic evidence and key data gaps in assessing the potential carcinogenicity of carbon nanotubes and nanofibers in humans. Crit Rev Toxicol 58(1):1-58.

Lam CW, James JT, McCluskey R, Arepalli S, Hunter RL (2006) A review of carbon nanotube toxicity and assessment of potential occupational and environmental health risks. Crit Rev Toxicol 36(3):189217.

Lee JH, Lee SB, Bae GN, Jeon KS, Yoon JU, Ji JH, Sung JH, Lee BG, Yang JS, Kim HY, Kang CS, Yu IJ (2010) Exposure assessment of carbon nanotube manufacturing workplaces. Inhal Toxicol 22(5):369381.

Legramante JM, Sacco S, Crobeddu P, Magrini A, Valentini F, Palleschi G, Pallante M, Balocchi R, lavocoli I, Bergamaschi A, Galante A, Campagnolo L, Pietrolusti A (2012) Changes in cardiac autonomic regulation after acute lung exposure to carbon nanotubes: implications for occupational exposure. J Nanomat 212:Article ID 397206.

Li Z, Hulderman T, Salmen R, Chapman R, Leonard SS, Young SH, Shvedova AA, Luster MI, Simeonova PP (2007) Cardiovascular effects of pulmonary exposure to single-wall carbon nanotubes. Environ Health Perspect 115(3):377-382.

Ma-Hock L, Burkhardt S, Strauss V, Gamer AO, Wiench K, van Ravenzwaay B, Landsiedel R (2009) Development of a short-term inhalation test in the rat using nano-titanium dioxide as a model substance. Inhal Toxicol 21(2):102-118.

Markowitz S (2015) Asbestos-related lung cancer and malignant mesothelioma of the pleura: Selected current issues. Semin Respir Crit Care Med 36:13.

Mercer RR, Hubbs AF, Scabilloni JF, Wang L, Battelli LA, Schwegler-Berry D, Castranova V, Porter DW (2010) Distribution and persistence of pleural penetrations by multi-walled carbon nanotubes. Part Fibre Toxicol 7:28.

Muller J, Delos M, Panin N, Rabolli V, Huaux F, Lison D (2009) Absence of carcinogenic response to multiwall carbon nanotubes in a 2-year bioassay in the peritoneal cavity of the rat. Toxicol Sci 110(2):442-448. 
Muller J, Huaux F, Moreau N, Misson P, Heilier JF, Delos M, Arras M, Fonseca A, Nagy JB, Lison D (2005) Respiratory toxicity of multi-wall carbon nanotubes. Toxicol Appl Pharm 207(3):221-231.

Nagai H, Okazaki Y, Chew SH, Misawa N, Yamashita Y, Akatsuka S, Ishiraha T, Yamashita K, Yoshikawa Y, Yasui H, Jiang L, Ohara H, Takahashi T, Ichihara G, Kostarelos K, Miyata Y, Shinohara H, Toyokunia S (2011) Diameter and rigidity of multiwalled carbon nanotubes are critical factors in mesothelial injury and carcinogenesis. Proc Natl Acad Sci U S A 108(49):E1330-E1338.

Nakanishi J. 2011. Risk assessment of manufactured nanomaterials: "approaches" - overview of approaches and results; carbon nanotubes (CNTs). New Energy and Industrial Technology Development Organization (NEDO).

$\mathrm{NCl}$ (2008) Working with nanomaterials. National Cancer Institute at Frederick.

NIOSH (1994) Asbestos by TEM. Cincinnati: Department of Health and Human Services, Centers for Disease Control and Prevention, National Institute for Occupational Safety and Health. Method 7402, Issue 2.

NIOSH (2003) Diesel particulate matter (as elemental carbon). Cincinnati: Department of Health and Human Services, Centers for Disease Control and Prevention, National Institute for Occupational Safety and Health. Method 5040, Issue 3.

NIOSH (2012) General safe practices for working with engineered nanomaterials in research laboratories. Cincinnati: Department of Health and Human Services, Centers for Disease Control and Prevention, National Institute for Occupational Safety and Health. Pub. No. 2012-147.

NIOSH (2013) Current intelligence bulletin 65 - occupational exposure to carbon nanotubes and nanofibers. Cincinnati: Department of Health and Human Services, Centers for Disease Control and Prevention, National Institute for Occupational Safety and Health. Pub. No. 2013-145.

Oberdörster G, Castranova V, Asgaharian B, Sayre P (2015) Inhalation exposure to carbon nanotubes (CNT) and carbon nanofibers (CNF): Methodology and dosimetry. J Toxicol Env Health B 18(34):121-212.

OECD (2016a) Multiwalled Carbon Nanotubes (MWCNTs): Summary of the Dossier. Paris: Organization for Economic Cooperation and Development. OECD Environment, Health and Safety Publications, Series on the Safety of Manufactured Nanomaterials. No. 68.

OECD (2016b) Single Walled Carbon Nanotubes (SWCNTs): Summary of the Dossier. Paris: Organization for Economic Cooperation and Development. OECD Environment, Health and Safety Publications, Series on the Safety of Manufactured Nanomaterials. No. 70.

Ong LC, Chung FFL, Tan YF, Leong CO (2016) Toxicity of single-walled carbon nanotubes. Arch Toxicol 90:103-118.

OSHA (1994) Occupational exposure to asbestos. Washington, DC: Occupational Safety and Health Administration. 29 CFR 1910.1001, 1915.1001, 1926.58.

Pacurari M, Lowe K, Tchounwou PB, Kafoury R (2016) A review on the respiratory system toxicity of carbon nanoparticles. Int J Environ Res Pub Health 13(1).

Pauluhn J (2010) Multi-walled carbon nanotubes (Baytubes): Approach for derivation of occupational exposure limit. Reg Toxic Pharmac 57(1):78-89.

Poland CA, Duffin R, Kinloch I, Maynard A, Wallace WAH, Seaton A, Stone V, Brown S, MacNee W, Donaldson $\mathrm{K}$ (2008) Carbon nanotubes introduced into the abdominal cavity of mice show asbestos-like pathogenicity in a pilot study. Nature Nanotechnol 3(7):423-428.

Rittinghausen S, Hackbarth A, Creutzenberg O, Ernst H, Heinrich U, Leonhardt A, Schaudien D (2014) The carcinogenic effect of various multi-walled carbon nanotubes (MWCNTs) after intraperitoneal injection in rats. Part Fibre Toxicol 11:59.

Ryman-Rasmussen JP, Cesta MF, Brody AR, Shipley-Phillips JK, Everitt JI, Tewksbury EW, Moss OR, Wong BA, Dodd DE, Andersen ME, Bonner JC (2009) Inhaled carbon nanotubes reach the subpleural tissue in mice. Nat Nanotechnol 4(11):747-751. 
Schinwald A, Murphy FA, Prina-Mello A, Poland CA, Byrne F, Movia D, Glass JR, Dickerson JC, Schultz DA, Jeffree CE, MacNee W, Donaldson K (2012) The threshold length for fiber-induced acute pleural inflammation: shedding light on the early events in asbestos-induced mesothelioma. Toxicol Sci 128(2):461-470.

Schulte PA, Kuempel ED, Zumwalde RD, Geraci CL, Schubauer-Berigan MK, Castranova V, Laura Hodson L, Murashov V, Matthew M. Dahm MM, Ellenbecker MJ (2012) Focused action to protect carbon nanotube workers. Am J Ind Med 55(5).

Service RF (1998) Nanotubes: The next asbestos? Science 281(5379):942.

Shvedova AA, Castranova V, Kisin ER, Schwegler-Berry D, Murray AR, Gandelsman VZ, Maynard A, Baron $P$ (2003) Exposure to carbon nanotube material: Assessment of nanotube cytotoxicity using human keratinocyte cells. J Toxicol Environ Health A 66(20):1909-1926.

Shvedova AA, Kisin ER, Mercer R, Murray AR, Johnson VJ, Potapovich AI, Tyurina YY, Gorelik O, Arepalli S, Schwegler-Berry D and others (2005) Unusual inflammatory and fibrogenic pulmonary responses to single-walled carbon nanotubes in mice. Am J Physiol Lung Cell Mol Physiol 289(5):698-708.

Shvedova AA, Fabisiak JP, Kisin ER, Murray AR, Roberts JR, Tyurina YY, Antonini JM, Feng WH, Kommineni C, Reynolds J, Barchowski A, Castranova V, Kagan VE (2008a) Sequential exposure to carbon nanotubes and bacteria enhances pulmonary inflammation and infectivity. Am J Respir Cell Mol Biol 38(5):579-590.

Shvedova AA, Kisin ER, Murray AR, Johnson VJ, Gorelik O, Arepalli S, Hubbs AF, Mercer R, Keohavong P, Sussman $\mathrm{N}$ and others (2008b) Inhalation vs. aspiration of single-walled carbon nanotubes in C57BL/6 mice: inflammation, fibrosis, oxidative stress, and mutagenesis. Am J Physiol Lung Cell Mol Physiol 295(4):L552-L565.

Shvedova AA, Kisin ER, Porter D, Schulte P, Kagan VE, Fadeel B, Castranova V (2008c) Mechanisms of pulmonary toxicity and medical applications of carbon nanotubes: Two faces of Janus? Pharmacol Ther 121(2):192-204.

Siegrist KJ, Reynolds SH, Kashon ML, Lowry DT, Dong C, Hubbs AF, Young SH, Salisbury JL, Porter DW, Benkovic SA and others (2014) Genotoxicity of multi-walled carbon nanotubes at occupationally relevant doses. Part Fibre Toxicol 11(6).

Simeonova PP (2009) Update on carbon nanotube toxicity. Nanomed 4(4):373-375.

Song ZM, Wang L, Chen N, Cao A, Liu Y, Wang H (2016) Biological effects of agglomerated multi-walled carbon nanotubes. Coll Surf B Biointerfaces 142:65-73.

SUVA. 2011. Grenzwerte am arbietsplatz 2011 (Occupational exposure limits 2011). Lucerne: Swiss Accident Insurance Funds (SUVA).

Takagi A, Hirose A, Nishimura T, Fukumori N, Ogata A, Ohashi N, Kitajima S, Kanno J (2008) Induction of mesothelioma in p53+/- mouse by intraperitoneal application of multi-wall carbon nanotube. J Toxicol Sci 33(1):105-116.

Tsai SJ, Ashter A, Ada E, Mead J, Barry C, Ellenbecker MJ (2008a) Airborne nanoparticle release associated with the compounding of nanocomposites using nanoalumina as fillers. Aerosol Air Qual Res 8(2):160-177.

Tsai SJ, Ashter A, Ada E, Mead J, Barry C, Ellenbecker MJ (2008b) Control of airborne nanoparticle release during compounding of polymer nanocomposites. Nano 3(4):1-9.

Tsai SJ, Ada E, Isaacs J, Ellenbecker MJ (2009a) Airborne nanoparticle exposures associated with the manual handling of nanoalumina and nanosilver in fume hoods. J Nanopart Res 11(1):147-161.

Tsai SJ, Hofmann M, Hallock M, Ada E, Kong J, Ellenbecker MJ (2009b) Characterization and evaluation of nanoparticle release during the synthesis of single-walled and multi-walled carbon nanotubes by chemical vapor deposition. Environ Sci Technol 43(15):6017-6023. 
Tsai SJ, White D, Rodriguez H, Munoz C, Huang CY, Tsai CJ, Barry C, Ellenbecker M (2012) Exposure assessment and engineering control strategies for airborne nanoparticles: an application to emissions from nanocomposite compounding processes. J Nanopart Res 14(7):989.

van Broekhuizen P, Dorbeck-Jung B (2013) Exposure limit values for nanomaterials - capacity and willingness of users to apply a precautionary approach. J Occup Environ Hyg 10(1):46-53. van Broekhuizen P, van Broekhuizen F, Cornelissen R, Reijnders L (2012) Workplace exposure to nanoparticles and the application of provisional nanoreference values in times of uncertain risk. J Nanopart Res 14(4):770.

Vietti G, Lison D, van den Brule S (2016) Mechanisms of lung fibrosis induced by carbon nanotubes: towards an Adverse Outcome Pathway (AOP). Part Fibre Toxicol 13(1):11.

Wang X, Xia T, Duch MC, Ji X, Zhang H, Li R, Sun B, Lin S, Meng H, Liao YP, Wang M, Song TB, Yang Y, Hersam MC, Nel AE ( 2012) Pluronic F108 coating decreases the lung fibrosis potential of multiwall carbon nanotubes by reducing lysosomal injury. Nano Lett 12:3050-3061.

Warheit DB, Laurence BR, Reed KL, Roach DH, Reynolds GAM, Webb TR (2004) Comparative pulmonary toxicity assessment of single-wall carbon nanotubes in rats. Toxicol Sci 77(1):117-125.

Wick O, Manser P, Limbach LK, Dettlaf-Weglikowska U, Krumeich F, Roth S, Stark A, Bruinink A (2007) The degree and kind of agglomeration affect carbon nanotube cytotoxicity. Toxicol Lett 168(2):121-131.

Wood JP (2000) Containment in the pharmaceutical industry. London, UK: CRC Press. 